THURSDAY, JULY 6, I87I

\section{SENSATION AND SCIENCE}

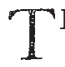
$\mathrm{HE}$ morbid craving for excitement, which is characteristic of mental indolence, as well as of effete civilisation, has led to the introduction of Sensation (as it is commonly called), not merely into our newspapers and novels, but even into our pulpits. It could not be expected that our popular scientific lectures would long escape the contamination. We have watched with regret its gradual introduction and development, and have often meditated an article on the subject. But now, when a splendid opportunity has come, we feel how unfit we are for the task. None but a Spurgeon can effectively criticise a Spurgeon; none but a Saturday Reviewer could be expected to tackle with delicacy and yet with vigour the gifted author of the "Girl of the Period." So we must content ourselves with the spectacle of the Rev. Prof. Haughton as criticised by himself. We have not been able to attend his recent lectures at the Royal Institution, but we have it on excellent authority that they were racy (i.e. sensational) in the extreme. Happily we find in the British Medical Foumal what is described as an authorised version of them. A few extracts from this will enable us to dispense with a great deal of comment. We shall first take the Science, and then permit the Sensation to speak for itself.

Prof. Haughton's subject is The Principle of Least Action in Nature; and we are told that he believes he has succeeded in discovering in this the true principle on which the Science of Animal Mechanics must be founded, and has been enabled to sketch out the broad outlines of its foundation.

Maupertuis's Principle of Least Action is indeed "well known to mathematicians," but is by no means easy of explanation to the ordinary reader. We can, therefore, sympathise with the lecturer in his repeated failures to make it intelligible. But we cannot admit any justification of the constant use of the same words, sometimes in one sense, sometimes in a totally different one. To a mathematician (Prof. Haughton speaks as at once mathematician, anatomist, medical man, natural philosopher, "expert" at shot-drill, the crank, and the treadmill, clergyman, \&c., \&c., and even as potential farmer and landlord-shooter !) we should have thought that, when once $x, y, z$, or whatever else, is introduced, it has and continues to have a definite meaning, until in a new problem it comes to be applied to something possibly quite different. How then can we account for such sentences as the following?-

"The great problem-the problem of doing a given amount of work with a minimum of effort."

"Nature aims at producing a given quantity of work with the least quantity of material."

"I could show that these [tendons of the legs and arms of animals] are constructed with a wonderful economy of force of the same kind as that with which the bee constructs its cell."

"By what force, or by what intelligence, do the limbs of animals describe their proper path? Who places the VOL. IV. socket of each joint in the exact position (which can be calculated with unerring certainty by mathematics) which enables the muscle to perform its allotted task with the least amount of trouble to itself?"

"The Principle of Least Action is that the arrangement and mutual position of all muscular fibres, bones, and joints must be such as to produce the required effect with the minimum amount of muscular tissue."

"Before proceeding to apply this principle of least action or least trouble to nature," \&c.

In all these extracts the italics are ours. If the reader but glance them over, he will not require to read the lectures to see what a very Proteus is this so-called principle. There is no knowing where to have it. It is a minimum, an economy, a least quantity, and what not ; sometimes of effort, sometimes of material, then of trouble, and anon of muscular tissue, or of force of the same kind as that with which the bee constructs its cell! But the most curious feature about it is that in none of its metamorphoses does it in the slightest degree resemble the least action of Maupertuis, with which it would seem throughout to be held as identical.

Even in his remarks on this perfectly definite mathematical question, Prof. Haughton commits a grave error, for he says :-

"If I take the points A and B in the planet's path, S representing the sun, I only require to know those points $A$ and.B, and the sun S, to calculate for you, from the Principle of Least Action-which I can do to the millionth part of an inch at each point of this orbit-the path that the planet must describe, on the supposition that it is a lazy, intelligent animal, trying to swim round the sun in such a manner as to give the least trouble to itself."

It seems to us that all that the principle of least action can tell us, is that, supposing the sun's attraction to vary inversely as the square of the distance, the planet will describe some conic section or other, whose focus is $S$, and which passes through $A$ and $B$. Which it will be of the innumerable conics satisfying these conditions, ellipse, parabola, or hyperbola (or possibly circle) there is nothing to indicate, within quadrillions of miles -yet we are told it can be done to the millionth of an inch!! As to what a "lazy, intelligent animal" (of course, not acted on by gravity) would do in "trying to swim [in what?] round the sun," we unfortunately possess no information. But this is merely another proof that we are dealing with Sensation where we looked for Science.

Here we have caught our instructor in a palpable and inexcusable blunder, and we could easily point out many others of a similar kind in his remarks on light, \&c. It is not so easy to do so, or rather to make the general reader aware that we have done so, when he leaves strictly mathematical applications, and plunges headlong into a wild sea of speculation without previous careful definition of his terms. These terms are, in fact, as he employs them, so elastic, that it is only by contrasting (as we did above) portions of his lectures with other portions in which the same words acquire other and different meanings, or in which different words are employed for the same meaning, that we see how excessively loose and slipshod is the whole affair. Another little group of quotations will admirably illustrate this :-

"The law of least action is attended to in every 
department of nature down to the most minute details. . . Not even one grain of material is eqer used, when less would suffice for the purpose."

This is, no doubt, admirable, and would suit the most frantic of the mischief-making teleologists. But, alas! like the Editor of the Little Pedlington Observer, "What in one line we state we retract in another." For there follows-

"We can demonstrate by mathematics that in the use of every such muscle [triangular, \&c.] there is a necessary loss of force. . . I have always maintained that beauty of form . . was one of the pre-existing conditions in the mind of the Contriver of the universe, as well as economy of force."

As intermediate to these two quotations, and in itself amusing from its bonhommie and condescension, we may take the following :-

"Nature, according to my principle, is entitled to employ these two forms of muscles whenever she pleases."

The reader may take our word that these are but single gems, selected from among many similar and often richer ones, mainly on the Principle of Least Trouble (in copying out for press).

As to really scientific matters, occasionally referred to in these lectures, we need merely mention that the author is ignorant of, or ignores, Dr. Pettigrew's extraordinary researches on wings and other adaptations for progression; researches which ought to be thoroughly mastered by any one who attempts to write on the subject of animal mechanics; and that, in his remarks on the strength of the uterine muscles, he seems to have entirely forgotten to notice how thoroughly least action theories (at least as applied by him) have been upset in a late number of the Dublin Quarterly Fournal of Medical Science.

We promised Science first and Sensation afterwards. In attempting to collect the Science we have got hold of little but Sensation: so we need give only one extract more. Would it have been considered possible (till the 23rd of last May) that a Dublin professor, an M.D., a D.C.L., an F.R.S., and a clergyman of the (till lately) Established Church, should, even in jest, speak as follows in the Royal Institution in London?-

". . . A brilliant idea came across my mind - . What in the world is to hinder me from taking a farm in Westmeath, deliberately and wilfully refusing to pay my rents, and in due time shooting my landlord, and, instead of using him as a New Zealand tenant would, dissecting him at my leisure?"

We have only to add that the British Medical Fournal, in publishing the above, conspicuously prints the remark :-

"In reproducing the ipsissma verba of the lecturer, and giving them a permanent place in scientific literature, an enduring service will be rendered to Science."

Which means, we hope, that all men, scientific or otherwise, will, once for all, take warning from this terrible example. If such be the result, Prof. Haughton will, indeed, not have lectured in vain. But if the British Medical Fournal intends its remarks to signify approval, we can say of it and of Prof. Haughton, in the language of Cervantes-

No rebuznaron en valde

El uno y el otro Alcalde.

\section{BASTIAN ON THE ORIGIN OF LIFE}

The Modes of Origin of Lowest Organisms: including a Discussion of the Experiments of $M$. Pasteur, and a Reply to some Statements by Professors Huxley and Tyndall. By H. Charlton Bastian, M.A., M.D., F.R.S., \&c. (Macmillan and Co., 187r.)

$\mathrm{T}$ may be as well to state at the outset that the present volume is not Dr. Bastian's long-promised work on "The Beginnings of Life ;" and it would have been better had some title been devised to prevent the confusion that will inevitably be caused by its appearance at this juncture. We have here, however, a condensed sketch of the whole controversy on Spontaneous Generation, and a statement of some very important researches conducted by the author since the discussion which followed Prof. Huxley's Presidential Address at Liverpool last September. It will be remembered that the objections to Dr. Bastian's experiments and to the results he deduced from them were twofold. It was said that we have no proof that these minute organisms (Bacteria, \&c.), or their germs cannot resist the heat to which they were subjected. It was also said that no proof was given that the supposed organisms found by Dr. Bastian in these boiled and hermetically sealed liquids were alive. The motions exhibited might be "Brownian" motions, and the experimenter probably found nothing in his vessels but what he put into them. The answer to these objections is now given. The test of vitality is said to be, not movement, which is admitted to be uncertain, but the power of reproduction. It is found that if a portion of liquid containing Bacteria is divided into two parts, one of which is bolled, and a drop from each of these portions is mounted as a microscopic object, under a covering glass surrounded by quickly-drying cement, the unboiled specimen exhibits a marked increase from day to day in the quantity of im. prisoned Bacteria, while the boiled specimen continues unchanged during the same time. Making use of this test of vitality, it was next ascertained what degree of heat was fatal to these low organisms. By using a lower and lower temperature, it was found that exposure to $140^{\circ}$ F. for ten minutes destroyed Bacteria, while after exposure to $13 I^{\circ} \mathrm{F}$. for the same time they rapidly multiplied. Somewhat higher organisms-Vibrios, Amcebce, Monads, Vorticellce, \&c., were, however, killed by exposure to $13 I^{\circ} \mathrm{F}$. for five minutes. It was subsequently ascertained that a four hours' exposure to a temperature of even $127^{\circ} \mathrm{F}$. destroyed Bacteria and Torulce. It is argued that, as in all these experiments the solutions used swarmed with Bacteria, \&c., in various stages of increase, their hypothetical "germs" cannot be supposed to have been entirely absent; and that we may therefore conclude that the "germ" has no greater power of resisting heat than the animal itself.

Dr. Bastian also criticises many of the experiments of Pasteur, and the arguments founded on them. He maintains that the corpuscles found by the latter to exist in the atmosphere, and which "resemble" spores of fungi, have never been proved to be such; and even if they were so proved, it would not account for the constant occurrence of Bacteria and other low organisms, whose "germs" are quite unknown, and which there seems no reason to believe could retain their vitality in a dry state 